Working

Paper

Department

of Economics

Ca’ Foscari

University of

Venice

Jan van der Borg

Antonio Russo

Towards a European Spatial

Policy for Culture 


\title{
Towards a European Spatial Policy for Culture
}

\author{
Jan van der Borg \\ University of Venice, Italy \\ Antonio Russo \\ University of Tarragona, Spain
}

\begin{abstract}
The European space finds itself in a moment of profound change. On one hand it is adapting to the challenges that are inherent to the global, post-industrial economy. A shift from traditional manufacturing towards innovative and service oriented activities, the relocation of economic activities to countries where inputs, in particular labour, are cheaper, an ageing population in combination with growing in migration from non-member countries have an immediate impact on the Europe of Regions. On the other hand, the extension of the European Union towards the East inevitably triggers complex and Europe-wide processes of social, economic and territorial reorganization.

In this context, the role of Cultural Heritage and Identity (CHI) may very well become a very crucial one. First of all, cultural heritage and identity are assets that are putting Europe in pole position with respect to the rest of the world, offering all European regions, no one excluded, unique social and economic development opportunities. They are important inputs for the creative industry and the tourist industry, two of the most important (the second already employs more than $10 \%$ of the global workforce) and dynamic sectors of the post-industrial economy. Moreover, cultural assets are typical place products that can not be separated nor moved from the regions they are located in. This makes these economic strictly bound to that location and impossible to re-localize. Thirdly, many cultural assets and traditions are not only points of reference for the local populations but for Europeans as such. Finally, in a Europe that is pursuing cohesion and competitiveness contemporarily, CHI forms sort of a natural bridge between two (apparently) not always compatible objectives. This means that $\mathrm{CHI}$ should become a cornerstone of European territorial policy.
\end{abstract}

Keywords

Cultural Heritage; Identity; Regional Development; Cultural Heritage Policies, Spatial Policies

JEL Codes

O52, R00, R58, Z10

Address for correspondence:

Jan van der Borg

Department of Economics

Ca' Foscari University of Venice

Cannaregio 873, Fondamenta S.Giobbe

30121 Venezia - Italy

Phone: (++39) 0412349135

Fax: (++39) 0412349176

e-mail: vdborg@unive.it

This Working Paper is published under the auspices of the Department of Economics of the Ca' Foscari University of Venice. Opinions expressed herein are those of the authors and not those of the Department. The Working Paper series is designed to divulge preliminary or incomplete work, circulated to favour discussion and comments. Citation of this paper should consider its provisional character.

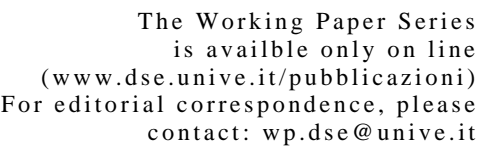

The Working Paper Series

is availble only on line

(www.dse.unive.it/pubblicazioni)

For editorial correspondence, please

contact:wp.dse@unive.it

Department of Economics

Ca' Foscari University of Venice

Cannaregio 873, Fondamenta San Giobbe

30121 Venice Italy

Fax: ++390412349210 


\section{Introduction $^{1}$}

The variety and richness of cultural heritage, both material as well as immaterial, is a resource that offers Europe a privileged position in the world. Its uniqueness, however, is not only an opportunity but an implicit threat as well. Being non reproducible, excessive pressure on heritage may compromise its (physical) integrity permanently and under the influence of societal and economic changes its authenticity may be definitively altered.

The ESDP fosters the wise management of our cultural heritage. It favours the sustainability of the use of the cultural heritage considered on one hand as an important vehicle of diffusion and knowledge of cultural details in a heterogeneous territory like Europe, guaranteeing regional and local identities; on the other hand as an important opportunity for economic development. The results of ESPON 1.3.3 on the territorial dimension of Europe's heritage may be a unique tool to implement the ESDP objectives related to the intelligent managing of European cultural heritage.

In fact, cultural heritage is considered by ESDP in its two fundamental dimensions: one part being cultural landscapes, the other one being heritage cities, cultural sites and monuments. Even though official definitions of cultural heritage suggest to adopt the widest notion of heritage, including immaterial elements and other outcomes of human creativity, it is very difficult to use such a broad definition when one wants to quantify the issues regarding the conservation of heritage and its consequences for regional planning.

It is beyond doubt that Europe takes a leading position in the importance of heritage cities, cultural sites and monuments as well as in the diversity of cultural landscapes with respect to the rest of the world. An indication for this might be the world-wide distribution of "protected landscapes" (IUCNcategory V) of which about 60\% are located in Europe. Moreover, according to UNESCO more than $80 \%$ of global cultural heritage is European. That said, cultural heritage is subject to wanted or unwanted transformations. Problems like the uncontrolled urban sprawl, increasing traffic volume, expanding commercial areas and mass tourism lead to a substantial devaluation of cultural heritage.

\footnotetext{
${ }^{1}$ This paper has been developed in the context of the ESPON 1.3.3 project on "The Role and Spatial Effects of Cultural Heritage and Identity" that was directed by the Department of Economics of the Università Ca'Foscari of Venice.
} 
Landscapes can be imagined as consisting of different layers, one being natural and the other one cultural. The natural landscape is the original landscape untouched by man, while the cultural landscape can be seen as a derivative natural landscape whose balance, structure and view is more or less influenced by human use. According to the intensity of human impact and transformation cultural landscapes can be further divided (see the figure below). Structural changes in agriculture on global scale with diverse regional effects are considered to be a main threat to traditional cultural landscapes, not only through more intensive agriculture but also owing to abandonment, resulting in a highly extensive use via fallow land and disforestation - above all in peripheral rural areas.

As far as the cultural heritage is concerned, a broad notion of cultural assets should be adopted, meaning that cultural richness can not be measured only in terms of "built" heritage, that is heritage cities, cultural sites and monuments, but immaterial elements should be considered too.

In spatial terms, the first category of assets includes, in fact, those with the deepest territorial roots. They are neither "footloose" nor reproducible. As a consequence, they are particularly fragile and highly sensible to their mode of use. These aspects turn out to be crucial for spatial planning purposes and therefore for the ESDP programme. Heritage cities, cultural sites and monuments have to be treated as a precious resource to the society and the community, rather than a constraint to social and economic development. Therefore, they require to be used in a balanced way, on one hand respecting the degree of complexity of their social and urban fabric, on the other hand keeping in line with the optimal use of highly non-reproducible resources.

The second type of endowment is represented by those assets that are both footloose and reproducible in theory. The analysis that has been presented in the previous parts of the Final Report, notwithstanding of the shortcomings that some of the statistical material presents, illustrates that there is a strong relationship between the presence of cultural heritage in the strict sense and cultural heritage in the broad sense. Only a small number of particular regions were able to create excellence or a cultural cluster from scratch (emblematic examples in this respect are the cities of Bilbao, Essen and Lille).

Figure 1 on the next page, slightly adapted by the TGP from the one developed in the context of the SPESP project 1.7, may be used to put the different aspects of cultural landscapes and heritage in their proper context and may therefore be used to give an interpretation of the regional typologies that emerged form our previous spatial analysis. 
Figure 1 - Structure of the Cultural Heritage.

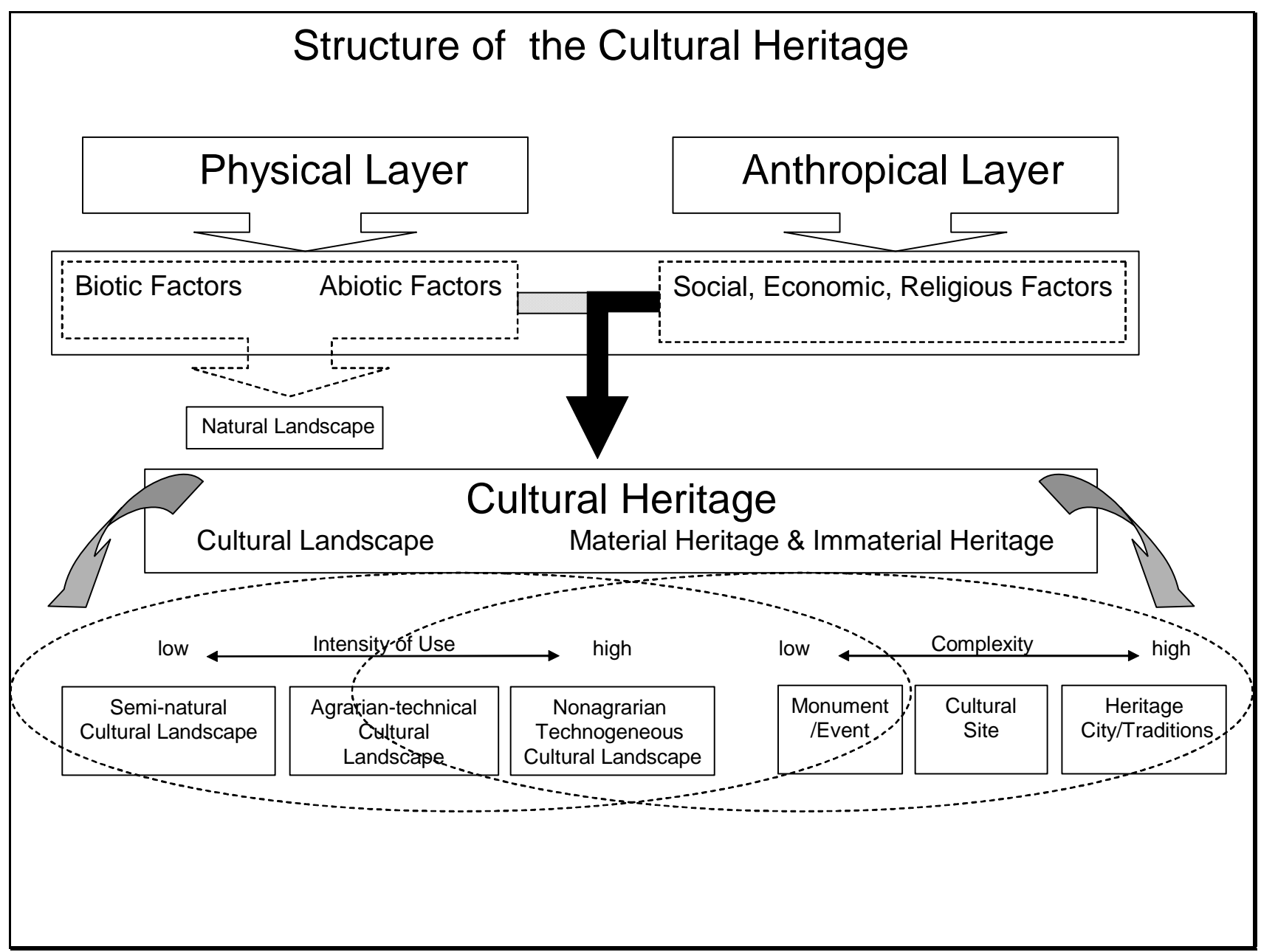

\section{Source: Our Elaboration of SPESP 1.7}

It has often been said that tourism is one of the most important ways of using the cultural heritage. Indeed, cultural tourism is by now one of the fastest expanding segments of the tourism market and brings very relevant social and economic opportunities as well as serious risks. But again, if not intelligently managed, tourism may generate important negative externalities, such as pollution and congestion as well as adverse social, economic and cultural impacts on the host community. Heritage cities, being cultural heritage in Europe in many cases an urban phenomenon, deserve some special attention because they are huge concentrations of material and immaterial cultural heritage. The appropriate utilisation of cultural heritage is therefore even more important, as heritage cities are extremely sensitive to the negative consequences of tourism. This is due to the fragile nature of the cultural assets, and to the potential conflict that 
there may exist between the use of the resources for tourist purposes and the normal functions a city has to provide for its inhabitants. Therefore, the sustainable use of the cultural heritage, especially in the case of heritage cities, demands an extraordinary planning effort.

The territorial scale of planning is a factor of crucial importance, as mass tourism is an economic phenomenon with inherent spatial features. Therefore, "tourist regions", being either cultural landscapes or areas socially and economically affected by the presence of individual parts like monuments, span different administrative units and can even have crossborder characteristics. In most cases, areas benefiting by the presence of the heritage do not correspond with the areas which bear the costs from that use. Seldom do local administrations or regional governments have the institutional capacity to plan for the sustainable development of tourism in its region of relevance. Planning for a sustainable use of the heritage requires in the first place to understand and to regulate the demand side, but in most cases this has not proved sufficient. An adequate attention should therefore be given to the management of the supply side, and to the environmental conditions that stimulate a desired pattern of visit. The provision of high quality facilities and infrastructure to attentive and sensible visitors who are willing to reward the value of the cultural heritage they have access to, granting the highest possible accessibility to everybody, is the key point of a sustainable tourism strategy.

This paper is structured as follows. In the next section a number of relevant policy issues will be presented. These issues directly stem from the analysis that can be found in the Final Report of the ESPON 1.3.3 project and the analysis of the case studies that are presented in the next section. In section 3, a synthetic overview will be given of existing European and National Cultural Policies and their priorities. In section 4, a number of suggestions for a European Cultural Heritage Policy will be given. Last but not least, in section 5 it will be shown that the information on both cultural heritage and cultural heritage policies is so fragmented, that already at the very base of policy making there is a need for a joint effort by the European Community (in particular EUROSTAT), the Council of Europe and UNESCO to construct an observatory that not only monitors the state of the cultural heritage sector in Europe continuously, identifies possible bottlenecks for their development and menaces for their conservation, and, hence, supply policy makers with the necessary information to manage heritage intelligently. This observatory may very well be an evolution of the results of the discussion within the TGP that led to the construction of the metadatabase on which the DSS for cultural policies has been based. 


\section{Towards a European Cultural Heritage Policy: The Crucial Issues}

The results that were presented in the Final Report of the ESPON programme regarding culture and identity, both in the form of maps, of regional typologies and of relevant case studies, have given rise to a number of reflections that ought to have important consequences for European Cultural Heritage policies.

From the spatial analysis, it became clear that the European territory is very rich of heritage and that heritage is one of the less polarised assets of Europe. Material and Immaterial heritage can be found almost everywhere, in both central as well as peripheral areas, in old as well as in new member states. Moreover, heritage may very well become the strategic production factor of the global, post-industrial economy, taking the place coal and iron ore possessed in the industrial economy. It also became clear from our analysis that heritage has a particular international dimension and is a typically cross-border phenomenon.

The case studies that were analysed by the TGP confirm and integrate what came out of the Europe-wide analysis, in particular as far as the role of identity and immaterial heritage is concerned.

In fact, the case of Ghent (Belgium) shows how important intangible heritage is for the social and economic texture of a city. In fact, the local cultural policymakers are now addressing the issue of how to conserve and even enhance the local identity even further. The cases of Amsterdam, Eindhoven, Rotterdam and The Hague, four Dutch cities that are actively pursuing a strategy that aims at creating a creative cluster, show how important networking is for the development of these clusters. Moreover, flagship projects in the form of events or huge urban revitalisation programmes, contribute to the formation of cultural clusters.

The case of the Cathedrals in the United Kingdom shows how to manage the potential conflict between different uses and users of (religious) heritage, a conflict that can only be solved, according to the authors of the case, if also the national government expresses itself explicitly in this sense. The German and the Swiss case studies are dealing with the role of minorities and their languages, intangible heritage, for their integration and hence for social development of regions.

The Portuguese case study deals with the issue of governance. It shows how important local authorities are in the process of cultural development and contains a warning for those who sustain that competition between cultural centres is healthy. Co-operation between regions seems to be an essential element of a sound cultural development strategy. The Spanish case that 
covers a Jewish heritage itinerary illustrates the importance of (crossborder) collaboration and of explicit tourism development strategies. The case of the Greek island of Rhodes shows how a marginal historical area (the medieval town) can become a thriving part of the regional economy, also thanks to tourism. The case of Venice in Italy shows how excessive pressure from visitors may threaten the integrity of the cultural heritage and the banalisation of the local identity. By specific planning policies aiming in distributing visitor pressure over space, the core of the tourist system may be safeguarded while its peripheries are being valorised. The other Italian case, the Province o Bolzano, shows that culture and identity are powerful vehicles of tolerance and understanding.

The two Czech cases illustrate the particular difficulties new member countries are experiencing in using $\mathrm{CHI}$ as inputs for social and economic development. Networking and strategic planning are seen as important tools to achieve that. The case of Zilinia (Slovakia) demonstrate how CHI can be easily implemented in a tourism development strategy. In this region, heritage is mostly non-urban which helps to boost the economy of the countryside. The case of the valorisation of religious heritage in South West Romania shows how international networking and strategic planning offer economic development opportunities. A major hindrance in this respect are the poor infrastructure and tourist facilities. The Polish case study regards three border regions in Poland, Lithuania and Latvia that are very diverse form an ethnic and cultural point of view. It is shown that this diversity, if managed properly (e.g. attention for the minorities in the media, valorisation of CHI of minorities), is not a menace but on the contrary an opportunity for development, especially of the tourist sector.

The French case of the "Jazz in Marciac Festival” illustrates the role of a distinct event for local social and economic development in a rural ambience. The festival not only creates cohesion among the inhabitants (the organisation counts 6 employees and 600 volunteers) but a significant economic spin-off as well: 5.500 bed-nights and 4.6 million Euros were generated by the festival. Community development and cultural development enforce each other. Another aggregating event is that of the Notte della Taranta, Salento, Italy. A regional tradition has been transformed in an event that attracts thousands of people and generates income and jobs for the region in the Italian Mezzogiorno. This success is welcome but is also endangering the authenticity of the tradition. The local government is now studying ways to find the right balance between use and conservation. Last but not least, the Finnish case of the Savonlinna Open Festival once more shows the importance of tourism for the valorisation of CHI. It illustrates what the impact of such an event may be and how, also through public financial support, this impact may even become more significant.

In general, this all leads us to two main conclusions for regional European heritage policies: 
Since European heritage is a typical place product and all Europeans are its stakeholders, cultural heritage ought to be an explicit element in all European spatial policies;

Since European heritage is an important asset for social and economic development that can be found virtually everywhere, the opportunities that heritage offers should be an increasingly important and explicit ingredient in assigning European funding.

To summarise, some of the crucial issues that ought to be addressed in an explicit way by such a policy are:

- In ESPON 1.3.3 evidence has been found that cultural excellence and regional competitiveness are interrelated. Policies that enhance cultural excellence might therefore improve the region's overall competitiveness;

- the analysis of the territorial distribution of the supply of $\mathrm{CHI}$ has shown that all the European member states, also the new member states, possess many -sometimes hidden- treasures. European, National and Regional policies ought to valorise them;

- the development of tourism brings about both costs and benefits. A number of case studies have illustrated that more should be done to limit the costs and internalise the benefits there were regions are engaged in tourism development policies;

- efforts to achieve more harmonisation regarding CHI in Europe should also include some degree of tax harmonisation. At a European level this harmonisation should be aiming at encouraging the involvement of private partners in the maintenance and "mise en valeur" of cultural heritage and landscapes;

- multicultural and multi-ethnical societies, are true assets for regions that strive for social and economic development and should be explicitly perceived as such in regional policies;

- in ESPON 1.3.3 evidence has been found that cultural heritage is concentrated in urban areas. A European heritage policy ought to explicitly recognise the role cities are playing in the cultural heritage sector. Moreover, coastal areas are endowed with more than average CHI supply. Also this fact should be taken into consideration when designing regional cultural policies;

- cultural landscapes and systems of cultural heritage do not respect administrative boundaries, and hence offer a variety of opportunities for cross-border, trans-national and interregional programmes and development projects;

- cultural development and the conservation of heritage require a sophisticated transport policy that stimulates accessibility when use of heritage should be encouraged and limited access when 
conservation is a priority. More European investments in the application of ITC in managing access are welcome;

- cultural heritage and cultural landscapes are basic conditions for the development of creative industries, the potential powerhouses of the post-industrial economy similar to what the textile and steel industries were for the industrial economy. Regional policies should favour the creation of the conditions of the growth of the creative industry;

- Europe presents a limited number of cultural clusters, or cultural hotspots, that may well become the continent's post-industrial growth poles;

- social and economic marginality may very well lead to cultural depauperisation, since social and economic decline may help to erode the critical mass that is necessary to maintain heritage. Marginality, as already mentioned, can be cured by striving for the valorisation of cultural assets but in some cases economic (i.e. increasing public expenditure) and social policies (social housing, for example) may be remedies that help conserve the built heritage and traditions indirectly.

In the next section an overview will be given of the current European and National cultural heritage policies in order to understand to what extent these issues are already embedded in the existing policies and whether there is a need for the intensification and the redirection of these policies.

\section{Existing European and National Cultural Policies: an Overview.}

The European cultural policy is very much a stealth policy, in the sense that specific actions regarding cultural development and cultural heritage are but a very small piece of a much larger amount of actions that are hidden in the different sectorial and spatial policies that are indirectly addressing cultural aspects (examples may be social policies that stimulate cultural employment; regional policies that address the problem of deindustrialisation by investing in cultural development projects that generate employment, agricultural policies that fund programmes related to rural heritage development, and so on).

In theory, the European Union's involvement in a common cultural policy is regulated by article 151 of the Treaty of Amsterdam that was adopted in 1997. This article clearly states that "the Community shall contribute to the flowering of the cultures of member states", co-operating actively with all the member states, third countries and other competent organisations in the sphere of culture, in particular the Council of Europe. The broad aims of these actions concern, on one hand, bringing the common cultural heritage to the fore, and, on the other, respect and promote the diversity of its cultures. 
In fact, the principal programmes developed by the European Commission that are directly addressing cultural development of Europe are two: Culture2000 and the European Capitals of Culture Programme.

The Culture2000 programme gathers the Raffaello (heritage), Arianna (literature) and Caleidoscopio (arts production) programmes. The programme was originally implemented for the 2000-2004 period but was extended and expanded for until 2007. The budget grew from approximately 200 million per year to 408 million per year in 2007 (www.europa.eu.int). The aims of this programme were: acceleration of the construction of a united Europe; acceleration of the process of globalization; acceleration of the entrance in the information society; creation of occupation and enforcing social cohesion and integration; stimulating economic development.

The following actions have been identified:

1. specific innovative ore experimental actions (not more than $45 \%$ of the budget);

2. integrating actions in the field of cultural coordination (at least $35 \%$ of the budget);

3. cultural events with a European dimension (10\% of the budget).

4. other initiatives (remaining budget).

Again, it appears that the attention for culture in the European Commission as such has been rather marginal. In 2007, approximately 1 Euro per inhabitant will be spend on explicit, direct cultural policies. Far below the average spending of the single member states. In fact the Culture 2007 programme partially corrects some of the flows in the programme. These flaws were principally (a) a difficulty in creating synergies with other organisations that deal with cultural development (not only the Council of Europe and UNESCO, organisation that will be dealt with hereafter), (b) a marginal and fragmented budget, and (c) too many objectives that were pursued contemporarily.

The European Capitals of Culture Programme runs successfully since 1985, the year that Athens became the first Capital of Culture. The programme pursues the following objectives:

- illustrate the cultural movements to which the cities in question have contributed;

- promote the organisation of international cultural events;

- sustain the creative industry;

- guarantee the involvement of the local populations;

- favour the diffusion of the event and promote the involvement of Europeans;

- promote the dialogue between European cultures and those of the rest of the world; 
- valorise cultural heritage, urban architecture and the quality of life in the cities in question.

Following the suggestions made by the Committee of Regions, the selection of cities has been modified in order to allow the new member states to express a cultural capital as rapidly as possible. In fact, between 2009 and 2018 two capitals will be selected, one from the old member states and one from the new member states, according to a precise calendar. Moreover, Decision 1419/1999/EC allows for third countries to forward candidates that might be designated as Cultural Capitals. The eagerness and interest of cities to become Capital of Culture is often explained by social-economic motives as much as by cultural motives. Cases such as Glasgow (1990), Lisbon (1994) and Lille (2004) are perfect illustrations of the philosophy that this project has been trying to emphasise: cultural and regional development, if properly managed, are walking hand in hand.

Other initiatives in the field of culture (arts rather than cultural heritage) regard the mobility of artists (for example the European Border Breakers Awards for musicians or the CIMET programme for performing artists, in particular dancers) and the European presence at art fairs, book fairs and film festivals.

Before reviewing the national cultural policies, some attention will be paid to the role the Council of Europe and UNESCO are playing in maintaining and valorising European Cultural Heritage.

UNESCO's WHC has adopted the following programme:

- Protecting and safeguarding Cultural Heritage. This first of all means reinforcing capacity-building for protection of World Heritage. Four objectives were formulated by the World Heritage Committee (Budapest 2002): strengthening the credibility of the World Heritage List; ensuring the effective conservation of world heritage properties, in particular properties in danger; building the capacities of the States Parties with regard to the protection of their world heritage properties, in particular by training the managers of those properties in management systems and plans and in risk management preparedness; enhancing communication by increasing public awareness and expanding partnership activities;;

- Identifying and safeguarding the intangible cultural heritage. This means to encourage Member States to ratify the 2003 Convention for the Safeguarding of the Intangible Cultural Heritage, to raise awareness among Member States, to assist them in safeguarding and promoting their intangible cultural heritage, mainly through the implementation of the Proclamation of Masterpieces of the Oral and Intangible Heritage of Humanity, the promotion and dissemination of the traditional music of the world, as well as the reinforcement of the Endangered Languages project; 
- Strengthening cultural policies, cultural industries and intercultural dialogue. This means: implementing a series of actions that draw on the principles of the UNESCO Universal Declaration on Cultural Diversity (2001) in order to promote the convention on the protection of cultural contents and artistic expressions, once adopted; assist Member States by elaborating, updating, implementing and promoting cultural policies, with particular attention given to the cultural dimensions in development policies so as to contribute more effectively against poverty, and particularly to support the pertinent activities of the New Partnership for Africa's Development (NEPAD); develop cultural indicators and collect related statistics and data in cooperation with the UNESCO Institute for Statistics (UIS) and national statistical institutes.

Although much of its efforts are extra-European, the activities developed by the UNESCO WHC are beyond doubt of relevance for a European regional cultural policy. Not in the least place because Europe hosts a large part of the World Heritage Sites that fall under UNESCO's control. Moreover, as the third point of he programme illustrates, it is currently working on a statistical observatory that may prove to be complementary to the one that is described in section 5.5 of this chapter.

The same is true for the activities developed by the Council of Europe. The Council of Europe is very much involved in policy development is at the core of the Council of Europe programme on Culture, both at the political level, to identify democratic, participatory and empowering policies to ensure access to culture for the public at large and through a better knowledge of other cultures, to encourage intercultural dialogue and at the field level, to see to it that our past is "harnessed" to our future, to ensure access and creativity and sustain Europe's cultural richness in its identities and diversities.

The Council of Europe's co-operation programme entails devising common policies and standards, developing and maintaining trans-national cooperation networks, providing technical support for member states and organising schemes to increase awareness of heritage values. In practice the Council of Europe is involved in: the protection and development of archaeology; the digitalisation of cultural property, the study of natural and technological hazards regarding heritage; the development and maintenance of European Cultural Routes; the European Heritage Days; the maintenance of the HEREIN network; the European landscape Convention; organisation of inter-ministerial conferences of ministers responsible for culture and for planning. Moreover, it has developed a technical co-operation programme that offers consultancy to heritage sites and cities in countries that are requesting specific assistance to solve particular problems. Given the descriptions above, it should become obvious why the pleas for a closer collaboration between the European Union, UNESCO and the Council of 
Europe, also with respect to a spatial cultural policy, are so strong. This collaboration, however, is currently still in its infancy.

A second important player in terms of $\mathrm{CHI}$ policies are the National Governments. As far as National Heritage Policies are concerned, the following priorities are pursued by the single European Countries (www.culturalpolicies.net; www.culturelink.org):

\section{Austria}

- address basic cultural needs: freedom of art and artistic expression, pluralism, quality, innovation, creativity, identity, internationalisation, stimulating general conditions for artists and possibilities for them to flourish, digitalisation;

- $\quad$ in terms of management: more transparency, promotion, competition, efficiency, public-private co-operation, flexibility, decentralisation, planning (establish contracts for several years), service orientation, evaluation;

- $\quad$ socio-political objectives: participation, equality, social security, representation, understanding the economic effects of the culture sector.

\section{Belgium}

- develop a cultural policy that is based on the principles of political and cultural democracy;

- $\quad$ priority is accorded to cultural participation and creativity, to the protection and promotion of a tolerant European culture, open to the world, intrinsically diverse and respectful of the minorities that contribute to global cultural development.

\section{Wallonian community}

- $\quad$ support for artistic creation and dissemination in the fields of performing arts (music, theatre, dance, entertainment arts), literature, visual arts, cinema, audiovisual productions;

- $\quad$ protection and promotion of the cultural heritage (except for property heritage, which falls within the competence of the Regions) including museums, folklore, ethnology, native or mother tongue languages, and cultural archives;

- territorial cultural development including cultural centres and public libraries;

- development of cultural democracy and participation in social and cultural life which includes support to youth and continuing education, cultural associations, intercultural activities, amateur arts;

- $\quad$ training support;

- democratisation of culture : introduction of different art forms to the different audiences;

- $\quad$ support for broadcasting (public radio and television, community television);

- press assistance;

- $\quad$ support for international activities.

Flemish community

- $\quad$ amateur arts;

- increased interest in the theatrical arts, plastic arts and literature;

- cultural co-operations;

- $\quad$ protection and preservation of cultural heritage;

- libraries;

- $\quad$ expansion of media service centres; 
- implementation of initiatives in the areas of book and film;

- public-sector and private sector radio and television broadcasters.

\section{Bulgaria}

- guarantee freedom of expression;

- creation of conditions for equal participation in cultural life;

- preservation and promotion of the culture of different ethnic and religious minorities;

- support for cultural education;

- support for international cultural exchange and intercultural communication.

\section{Cyprus}

- democratization of culture;

- cultural relations with foreign countries.

\section{Czech Republic}

- to harmonize the recent political and economic change also in the field of culture;

- to structure new responsible bodies and institutions;

- the guarantee of cultural democracy for authors and performers;

- freedom of authentic expression and provision of conditions for creative work;

- the guarantee of conditions for artistic and cultural innovation; to create the conditions for the preservation and development of Czech identity;

- to make use of the advantages of the market economy to support and promote, and simultaneously also to protect, cultural values;

- to find new public and private partnership.

\section{Denmark}

- the aim is involving as many people as possible in cultural activities;

- schools and education play an important rule in involving people in culture;

- decentralization and some clarification in the division of labours among government levels;

- to create the establishment of independent cultural institutions in different regions;

- the right to decide to local bodies and the encouragement of the kind of cultural activities that arise spontaneously all over the country;

- new legislation, that establishes that cultural policy in Denmark should be based on a much wider concept of culture than the traditional one;

- cross-sectorial cultural initiatives involving cooperation between the arts and cultural institutions on the one hand and popular culture on the other.

\section{Estonia}

- implementation of Council of Europe standards;

- co-operation between private and public initiatives;

- protection of cultural heritage is seen as an important task both by state officials and the public, the resources from the state budget, i.e. the actual possibilities for protection, have diminished;

- restrictions and obligations to the owner of a monument or immovable located in a protected zone;

- government may also offer the owner a substitution for the area where the monument is situated. 


\section{Finland}

- $\quad$ affirm that the national identity is the corner stone of society and culture;

- $\quad$ promotion of artistic creativity;

- $\quad$ to emphasise creativity and innovations and their contribution to economic growth;

- $\quad$ to expand participation in cultural life;

- $\quad$ to reinforce the arm's length approach in art policy (decentralisation);

- $\quad$ protection of minorities, including the Swedish-speaking Finns, can be seen as an aspiration for cultural diversity;

- $\quad$ local culture as a positive factor in regional development;

- 2015 strategic plan of Ministry of education and culture:

-safeguarding equal access to education and culture; -promoting intellectual growth and learning; -enhancing opportunities for sharing and participation; -providing resources for improving the cultural and economic competitive capacity in Finnish society; -opening up new channels in order to diversify the Finnish impact in the international community;

-improving effectiveness in cultural sector.

\section{France}

- developing participation in cultural activities and broadening access to culture in general;

- $\quad$ diversification in the mode of access to art linked to the growth of the audio-visual industry;

- major emphasis on works in the French language;

- regulation of Web content.

\section{Germany}

- $\quad$ stimulate participation in cultural life;

- $\quad$ support for culture institutions in the new capital city Berlin;

- $\quad$ giving greater competence for cultural affairs to the Federal Government;

- $\quad$ streamlining and optimising cultural funding among the different levels of government;

- $\quad$ passing of new laws in the fields of copyright and taxation for foundations as well as re-enforcing social insurance provisions for self-employed artists;

- $\quad$ repatriation of unlawfully seized cultural assets;

- implement UNESCO Convention on the Protection and Promotion of the Diversity of Cultural Expressions;

- $\quad$ constitutional protection for culture;

- greater civic commitment to culture;

- $\quad$ responding to a cultural public with increasingly diversifying needs;

- migrants, cultural diversity, intercultural co-operation;

- $\quad$ outsourcing public sector tasks.

\section{Greece}

- $\quad$ equal access and participation in cultural life, in particular for young people;

- $\quad$ promoting identity and diversity;

- $\quad$ supporting for creativity. 


\section{Hungary}

- cultural development of the countryside;

- more culture in childhood;

- reaching new groups of public;

- action plan for heritage protection;

- bringing cultural heritage closer to life;

- promoting Hungarian talent at home and abroad;

- contemporary innovation for the classics of the future;

- culture boosts the economy.

\section{Ireland}

- assist artist to realise their artistic ambitions;

- strengthen arts organisations countrywide so as to secure the basis of a vibrant and stable arts community;

- make it possible for people to extend and enhance their experience of arts;

- promote and reaffirm the value of the arts in society;

- ensure the Arts Council works effective;

- implement the National Cultural Institutions Act, 1997;

- review the Irish Manuscript Commission;

- encourage and promote film-making in Ireland;

- support the further development of the arts and culture infrastructure.

Italy

- the protection and enhancement of heritage;

- the promotion of reading and books and libraries;

- the promotion of urban and architectural culture;

- the promotion of cultural activities, with particular reference to the performing arts and cinema and the visual arts;

- the support of artistic research and innovation;

- higher training in all cultural disciplines;

- the diffusion of Italian culture and art abroad.

\section{Latvia}

- analysis of the achievements of the previous cultural policy;

- analysis of the present socio-economic and political environment in Latvia;

- consideration of trends and issues of cultural policies in other countries internationally, for example due to the enlargement of the EU, the processes of globalization, and the development of new technologies and the information society.

\section{Lithuania}

- to improve the administrative system on national heritage protection, to draft the long-term strategy for heritage protection;

- to expand democracy in cultural life;

- $\quad$ to set the basic principles for state's support to art and artists;

- to draw up the so-called National Programme of Culture and to develop an Action Plan for its implementation;

- to pursue investigations in the cultural sector; 
- to stimulate regional cultural development and cooperation of tourism and cultural institutions;

- $\quad$ to develop the information society and access to culture.

\section{Luxemburg}

- decentralization of culture management in local communities;

- $\quad$ to develop and implement a regional cultural policy in cooperation with local communities;

- $\quad$ involvement in international cultural relations and more cooperation with other countries;

- $\quad$ to implement cultural professionalism.

Malta

- $\quad$ the intangible values of culture cannot be divorced from the cultural heritage;

- the increase professionalism in the sector and meet approved standards in certain key areas of museum management, collection care and public services;

- $\quad$ the need to develop a comprehensive inventory of underwater sites and other cultural assets is considered a high priority;

- $\quad$ reinforce military heritage which consists of architectural creations with a long history of involvement in military events of the Mediterranean;

- CHIMS creates a new knowledge-based context for understanding, managing and disseminating data concerning cultural heritage.

\section{The Netherlands}

- $\quad$ "Culture as Confrontation" is the title of the cultural policy document (1998-02): three objectives cultural diversity, audience-reach interacting with a broader more diverse audience, cultural entrepreneurship;

- a strict division between the state domain and the commercial market is no longer realistic;

- $\quad$ policy document 2002-2004 "More than the Sum":

- $\quad$-less bureaucracy and more individual responsibility in the cultural system;

- -more connection and interaction in cultural life;

- $\quad$-reinforcing the cultural factor in society, more relationship between culture and economy;

- Cultural Outreach Action Plan, the aim of which is to involve more people in culture, especially new audiences such as immigrants and the young;

- $\quad$ more co-operation between central government, provinces and municipalities.

\section{Norway}

- union-oriented and politically influential artists associations;

- $\quad$ public subsidies to artists which are usually explained by socio-political arguments;

- decentralisation;

- democratisation;

- distribution based on local self-governments, egalitarian values;

- $\quad$ stimulate the play of market force;

- the artist must be on an equal footing with other groups in working life;

- the State considers itself as the employer of artists and grants them the right to negotiate on issues of labour, salary and social rights. 


\section{Poland}

- effective growth of sound management principles in the field of culture;

- introduction of innovative solutions in the organisation of the system of cultural activities, and in the system of rendering culture more popular and accessible;

- decrease in regional imbalances in the development of culture;

- increase in participation and equalisation of access to artistic education, cultural goods and cultural services;

- improvement of conditions for arts activity;

- effective promotion of creative activity;

- safeguarding cultural heritage and active preservation of monuments;

- decrease in the civilisation gap through modernisation and development of the cultural infrastructure.

\section{Portugal}

- $\quad$ protection of heritage;

- promotion of reading;

- development of national networks of activities and facilities;

- attention for the culture and identity of ethnic minorities;

- application of information technologies in arts;

- arts education.

\section{Romania}

- the decentralisation of the administration of culture, the reorganization of the cultural institutions by entering into partnership with local public authorities and with the structures of civil society;

- the establishment of a new financing mechanism for programmes and projects;

- selection of cultural landmarks in view of regenerating the community around the significant symbol;

- protection of the community's material memory and the community's economic development in terms of new jobs, services development and promotion of the entrepreneurial spirit.

\section{Slovakia}

- to speed up the slow transformation of responsibility from state to local institutions;

- to solve management problems;

- to solve many questions concerning the financial assistance of the government; municipality, sponsors, gift makers, as well as further requirements and events, connected with the transformation from earlier government (state) "Cultural heritage monopoly" to private ownership and competitive environment, as well a increased participation of municipalities, citizens and citizens' associations;

- to decide in the first level in the administrative hearings in the area of protection, as described by law;

- to perform and coordinate documentation, education, training, publishing, propagation in the area of protection.

\section{Slovenia}

- balance the constitutive and the instrumental role of culture in society;

- preserve and develop the Slovenian language; 
- promote cultural diversity;

- ensure access to cultural and spiritual assets;

- improve conditions for artistic creations;

- encourage culture industries and implement information technology.

Spain

- investment in traditional cultural infrastructures at the expense of potential contemporary models that better respond to public demands;

- new government priority: encouraging cultural consumption over amateur or community practices;

- looking for new resources and a greater efficiency in government cultural intervention;

- need to re-direct public policy towards encouraging private cultural intervention;

- promotion of a global vision in the protection of cultural industries;

- formulate a clear position concerning the regulation of communication media;

- solve the conflicts in relation centre-periphery and the lack of communication and co-ordination towards dialogue and raising awareness of Spain's cultural \& linguistic diversity;

- policies explicitly serving the capital, Madrid, supporting major cultural infrastructure of the city;

- $\quad$ support to similar (minority) schemes in Barcelona, Valencia, Seville and Bilbao;

- enhance internationality and openness;

- reinforce the presence of Anglo-American cultural content in industries and in local creativity production.

\section{Sweden}

- recognising the role of culture as a factor of regional growth, the Swedish government understands that culture activities have both short- term effect in the form of an increased number of jobs and long term for improved attractiveness, creativity and development of identity;

- promote better access to culture for youth and disadvantage people;

- assure that national museums offer free entrance for visits to their permanent exhibitions;

- ministries of Finance and of Culture and of Education are jointly investigating the effects of Value Added Tax regulations on the use of cultural goods and services, including reading habits;

- stimulate interaction between all levels of government and other stakeholders and promote international cultural exchange and meeting between different cultures.

\section{Switzerland}

- implement a cultural policy (i.e. on all regional levels) that focuses on the broad population, on the artists, on cultural institutions and projects;

- promotion of culture and enforce a public discussion on culture, forming adequate basic conditions and for the interests of the artist;

- cultural policy is linked to other policy-fields, such as city-planning, financial and fiscal policy, cultural industries, etc;

- cultural policy means more than structuring a determined field; it always has an effect on the society as a whole;

- the promotion of identity, creation, diversity and access to cultural life. 


\section{United Kingdom}

- further enhance access to culture and sport for children and give them the opportunity to develop their talents to the full and enjoy the benefits of participation;

- increase and broaden the impact of culture and sport, to enrich individual lives, strengthen communities and improve the places where people live;

- maximise the contribution which the tourism, creative industries can make to the economy;

- modernise delivery by ensuring that DCMS sponsored bodies are efficient and work with others to meet the cultural and sporting needs of individual and communities.

Although the descriptions of the policy priorities remain necessarily general, the overview of national policies illustrates that not only the definitions used to identify heritage are varying considerably among countries, but that the priorities are very different too.

Nevertheless there are a number of priorities that can be found in most of the national policies exposed previously. The first is the aim to improve the access to culture in general and that of special target groups, such as minorities and youth, to culture in particular. Secondly, many countries are considering to make heritage policies more business-like. Thirdly, cultural policies seem to have a distinct territorial character. Not only are a number of countries shifting the responsibilities for cultural development from the national level to the local level, in some cases national policy explicitly deals with the socio-economic potential of culture for the country's regions (Hungary, the Netherlands, Sweden and the United Kingdom in particular). Last but not least, identity plays and important role in almost all national cultural policies.

Specific themes that can be found in the national policies are, among others, the need for conservation (especially for countries that have demonstrated to possess large amount of historical heritage) and for a better knowledge of the phenomenon, tourism development (Lithuania, UK), creative industries, devolution, involvement of private parties, new media. The differences between the cultural policies old and the new member states are less pronounced as might be expected; in terms of priorities, the latter seem to be slightly lagging behind the former in the sense that the emphasis on getting the cultural sector properly organised is more strongly felt in the policies of the new member states.

Also the national expenditure dedicated to cultural policies in general and cultural heritage in particular varies quite a lot per country, as is illustrated by the following table on the next page. 


\begin{tabular}{|c|c|c|c|c|}
\hline Country & Year & Total Expenses (EURO) & $\begin{array}{l}\text { Expenses per } \\
\text { Inhabitant (EURO) }\end{array}$ & $\begin{array}{l}\text { Expenses as } \\
\% \text { GDP }\end{array}$ \\
\hline Austria & 2002 & 1.888.820.000,00 & 234,20 & $0,88 \%$ \\
\hline Belgium & 1999 & $2.505 .125 .000,00$ & 245,00 & $1,05 \%$ \\
\hline Bulgaria & 2004 & 70.689.923,08 & 8,54 & $0,66 \%$ \\
\hline Croatia & 2003 & 95.961.757,00 & 21,43 & $0,37 \%$ \\
\hline Denmark & 1996 & $1.197 .524 .552,67$ & 226,17 & $0,82 \%$ \\
\hline England & 2004 & 8.626.275.177,30 & 176,39 & $0,50 \%$ \\
\hline Estonia & 2003 & 159.876.293,93 & 113,23 & $1,90 \%$ \\
\hline Finland & 2001 & $745.000 .000,00$ & 140,35 & $0,54 \%$ \\
\hline France & 2000 & $5.780 .000 .000,00$ & 98,94 & $0,90 \%$ \\
\hline \multirow[t]{2}{*}{ Germany } & 2000 & $7.950 .000 .000,00$ & 96,74 & $0,39 \%$ \\
\hline & 2003 & 8.190.000.000,00 & 99,30 & $0,39 \%$ \\
\hline Greece & 2001 & 714.049.000,00 & 37,56 & $0,32 \%$ \\
\hline \multirow[t]{2}{*}{ Hungary } & 2003 & $302.476 .190,48$ & 29,15 & $0,41 \%$ \\
\hline & 2004 & $364.000 .000,00$ & 35,70 & $0,50 \%$ \\
\hline \multirow[t]{2}{*}{ Ireland } & 2003 & $105.980 .000,00$ & 33,15 & $0,07 \%$ \\
\hline & 2004 & $215.550 .000,00$ & 59,44 & $0,15 \%$ \\
\hline Italy & 2000 & $6.754 .200 .000,00$ & 118,00 & $0,57 \%$ \\
\hline Latria & 2004 & 82.340.091,04 & 26,87 & $0,58 \%$ \\
\hline Lithuania & 2003 & $96.811 .594,00$ & 27,70 & $0,60 \%$ \\
\hline Luxembourg & 1993 & $24.844 .720,50$ & 64,59 & $0,15 \%$ \\
\hline Malta & 2003 & $96.815 .541,86$ & 43,62 & $1,45 \%$ \\
\hline Moldova & 2003 & 16.155.216,00 & 3,69 & $0,08 \%$ \\
\hline \multirow[t]{2}{*}{ The Netherlands } & 2001 & $3.373 .000 .000,00$ & 214,36 & $0,60 \%$ \\
\hline & 2003 & $3.621 .000 .000,00$ & 161,00 & $0,50 \%$ \\
\hline Northern Ireland & 2004 & 140.141.843,97 & 84,99 & $\mathrm{Na}$ \\
\hline Norway & 1994 & 17.264.276,23 & 3,94 & $0,01 \%$ \\
\hline Poland & 2004 & $810.025 .744,00$ & 26,10 & $0,47 \%$ \\
\hline \multirow[t]{2}{*}{ Portugal } & 2001 & $1.551 .700 .800,00$ & 157,17 & $1,20 \%$ \\
\hline & 2003 & 632.687.000,00 & 64,15 & $0,43 \%$ \\
\hline Romania & 1998 & 49.099.078,14 & 2,18 & $0,13 \%$ \\
\hline Scotland & 2004 & $550.415 .602,84$ & 107,16 & $\mathrm{Na}$ \\
\hline Slovenia & 2003 & 196.899.028,00 & 100,00 & $0,81 \%$ \\
\hline Spain & 1995 & 2.082.435,71 & 0,05 & $0,0004 \%$ \\
\hline Sweden & 2003 & 1.908.359.928,85 & 215,53 & $0,71 \%$ \\
\hline Switzerland & 2002 & $1.500 .820 .007,93$ & 205,30 & $0,53 \%$ \\
\hline Ukraine & 2004 & 349.540.200,00 & 6,90 & $0,42 \%$ \\
\hline Wales & 2004 & $240.520 .567,38$ & 82,46 & na \\
\hline
\end{tabular}

Sources: www.culturalpolicies.net; www.culturelink.org; ww.europeanheritage.net

Notwithstanding the obvious problems related to the comparability of the information (for example, not all policy levels have been represented in the figures presented above; the role of regional and local administrations in financing cultural development (Spain seems to be an obvious example of this phenomenon) in financing culture can not be neglected), the 
expenditure per inhabitant and the expenditure as percentage of GDP allow us to identify the countries that tend to invest more in culture than others: Austria, Belgium, Denmark, England, Estonia, Finland, Italy, the Netherlands, Portugal, Scotland, Slovenia, Sweden and Switzerland spend more than 100 Euro per inhabitant, while Belgium, Estonia, Malta and Portugal spend more than 1\% of GDP on culture. France and Germany spend almost 100 Euro per inhabitant and especially France comes with its $0,90 \%$ of GDP spend on culture very close to the big spenders. The new member countries, with the exception of Estonia and Slovenia, fall far behind.

Given the principles of subsidiarity, the European Cultural Policy should complement and integrate the policies that the different countries are implementing. However, the principle of subsidiarity should not be interpreted too narrow, as Smiers (2002) has argued. National heritage is per definition also European heritage. The European Community should therefore be actively seeking synergies with member states, third countries and other organisations that are concerned with culture, such as the Council of Europe (on issues regarding the valorisation of CHI) and UNESCO (on issues regarding the conservation of $\mathrm{CHI}$ ). On what basis this may be done will become clearer in the next sections.

\section{A European Spatial Policy to render its Cultural Heritage Use Sustainable: the Delicate Balance between Valorisation and Conservation}

In a society that develops increasingly fast, cultural heritage may constitute one key stabilising factor for the social past and the collective memory of our society while, on the other hand, culture and the cultural heritage themselves are subject to changes. It is necessary to ensure that future generations may continue to benefit from the stabilising effect. However, the emphasis on "being there" instead of on "being used" has sometimes led to a conservative, passive attitude towards heritage conservation. Progress and heritage use, on the one hand, and heritage conservation on the other, are often regarded as incompatible.

Gradual changes in this attitude have been observed. Lately, a new vision regarding heritage conservation emerged, in which the presence of heritage alone is not sufficient, but heritage itself becomes a major impulse for social and economic progress, progress from which heritage itself benefits.

Several new international conventions regarding heritage respond to these juxtapositions by stating that the "wise" use of heritage ought to be promoted. By wise use they understand: use the many opportunities cultural heritage offers, while respecting the ethical aspects of heritage. The heritage is closely connected to the place where it is located and the local 
community. Making the heritage accessible and recognisable to the wider public provides huge opportunities of enrichment, such as community awareness and cohesion, social-economic regeneration for deprived areas, employment in the lowest sectors of the job market, image improvement of the place. In fact, $\mathrm{CHI}$ is the glue that may help to keep local and regional societies together. The revenue generated through the use of the heritage is a major means to finance the up-grading and the conservation of the heritage itself, and can be redistributed to improve the socio-economic conditions of the community.

Another discussion that is going on is about value of the heritage. In times where (public) budgets are limited there are doubts whether only outstanding or also ordinary landscapes or landmarks of cultural heritage deserve to be taken care of.

According to the ESDP, cultural assets shall be developed or be preserved by appropriate methods, partly even be renewed. To further develop means of protection, management and planning, in this third interim report a number of relevant indicators were developed to measure the intensity and the diversity of the presence of cultural heritage and their use in European space.

Above all, those responsible for spatial planning are requested to further work on the cautious "mise en valeur" of cultural assets and particularly to promote the concepts of cultural landscapes and of built cultural assets, as these make up an important part of our historical development and the common European heritage and identity.

In general, there is often the discussion which of the two ways should preferably be followed:

- Is the main goal that of conserving the cultural heritage in its actual state, in a sort of 'musealisation' approach, limiting accessibility?

- Or should one rather follow the line of further development of accessibility, especially by tourists, to heritage?

The first approach is often criticised as a management that prevents the inherent evolution and development; the price to pay in the second one is that cultural heritage undergoes an alteration and changes its character, or may even disappear. Neither of the approaches is completely correct or completely wrong.

Since there are different types of heritage with different significance and degree of endangering, they require different treatment. In general, one can distinguish:

- Legal measures and protection;

- Planning; 
- Concrete regional cultural policies.

Legal Measures and Protection apply to all cultural heritage and in particular that with a special or outstanding value. While this approach is in most countries and also on an international level well advanced when related to landscapes with valuable natural habitats, the member states should be encouraged to set up proper legal means for the protection of cultural landscapes as well. On the European level, the European Landscape Convention which is being prepared for adoption serves as an adequate means. Many conventions, for example those of UNESCO and the Council of Europe, already cover the built heritage.

However, while since 1993, the UNESCO-World Heritage List includes cultural landscapes of outstanding universal value, other systems that identify the areas that should be protected are needed in order to underline the delimitation of cultural landscapes of European and national (referring to EU-member states) rank. The classification of the regions of Europe according to the pressure from potential users with respect to the supply that has been proposed in this report

But it must be very clear that (rigorous) protection measures can only cover a very limited part of this cultural heritage, because most parts of the cultural landscape and built heritage have evolved over a long time and for future development they need the economic and social functions imposed on them by the people living there. Hence, protection does not mean no use at all, but the necessity to make the use compatible with the requirements of the cultural assets -especially given their fundamental role in social and economic development- and hence sustainable. The fact that the different countries apply very different criteria to identify heritage renders spatial planning less effective. In contributing to some sort of harmonisation of these criteria lies an important task for the European Community.

Planning is a second instrument. In the sector of spatial planning the rating of cultural landscapes has increased considerably, especially at EU-level (see the ESDP of the European Commission). If this is taken as a standard, spatial planning in the member states still has considerable work to do in order to put the objectives into concrete terms with higher formal obligations. Instruments of spatial planning should be revised and supplemented. In accordance with the precautionary principle, one example could be the protection of open areas through the instrument of priority/reservation sectors, as has been discussed in Germany. Even if in most countries explicit attention is paid to registered monuments in the planning process, many cultural sites and heritage cities are not yet sufficiently covered. This is especially the case in new member countries. They have, understandably, given priority to development and much less to conservation. This may prove very damaging in the long rung. 
In connection with the conservation and development of cultural landscapes, spatial planning should also aim at taking on an interdisciplinary coordination and moderation function. One primary task would be to create a co-ordination between the economic concerns, multi- and intra-sector plans of agriculture and the resource-protecting plans of nature conservationists. Moreover, attention should be paid to the possible relationships between built heritage conservation and, for example, housing policies and urban regeneration policies.

Land use planning includes controlling the changes in the use of land and in imposing restrictive conditions on certain forms of land use. It is necessary that standard routines of environmental impact assessment at all spatial levels as well as in a strategic sense should not only include natural aspects, but also the cultural heritage.

Land consolidation, which has for long applied solely with the aim of improving agricultural efficiency, could be further adapted to take other objectives, including landscape conservation, into account. Another possibility would be respecting landscape aesthetics for leisure purposes and attractiveness as an important "soft" location factor. Also the implementation of primary infrastructure for tourism development could be encouraged. An example would be installing food and cycle paths or the promotion of rural tourism facilities.

These general considerations should be the foundation of Europe's regional cultural policy. Concerning the policies regarding cultural heritage, direct and indirect actions may be distinguished. Direct actions include the purchase of land or monuments by public agencies or NGO's, whereby the desired form of management and co-ordination is secured.

EU-Community initiatives under the ERDF Structural Funds and agricultural support measures belong to the indirect management actions, contributing to and influencing the management of certain cultural landscape types. Thus, in all actions taken, the effects on cultural landscapes should be considered. Policies regarding cultural heritage in urban environments not only regard the actions taken by DG $\mathrm{X}$, but also in the schemes developed by other DGs (for example environmental policies, cultural tourism development; strengthening infrastructural development close to heritage sites, and so on). A considerable influence on the shaping of large parts of our cultural landscapes and heritage can be attributed to the LEADER and INTERREG programmes.

Following among others Smiers (2002) and the Prodi Working Group on Cultural Heritage (2004), at this point of the report a number of concrete general policy recommendations can be made:

- encourage member states to sustain projects that foresee in the collaboration and the movement of artists, since they are, following 
the work of for example Florida and of Landry, the principal input of the creative industry and provokers of cultural innovation and development;

- bridge the gaps regarding the attitude towards culture between the old and the new member states as soon as possible, for instance by making part of the Structural Funds available for projects that intend to safeguard the cultural identity of the latter and to help to avoid that an excessive belief in market forces and economic development puts the integrity of their cultural heritage in danger;

- support international and cross-border initiatives intensively;

- guarantee the broadest possible access to culture;

- provide funding for the conservation of cultural heritage and implement measures, not necessarily in the field of culture that render the conservation of cultural heritage easier (for example by combating acid rain, monuments deteriorate much more slowly);

- stimulate the co-operation with other parts of the world, in particular the bordering states. Culture is a powerful vehicle of tolerance and mutual understanding that should be used fully;

- adopt concrete policies that counter the smoothening effects of globalisation and help to maintain cultural diversity.

A first important step towards the introduction of an explicit spatial dimension in the European cultural policy has been made with the classification of NUTS III regions for which the use of heritage may not be sustainable, regions where this use is sustainable and the regions that are not using the potentials cultural assets fully. Following the basic philosophy of the ESPON 1.3.3 project, again a distinction was made between regions where social and economic development potentials may be lost because of insufficient use of heritage and regions that may suffer from an excessive pressure on their cities, sites and monuments.

In the first type of regions further tourism development should internalise the benefits of the presence of cultural heritage further; in the second emphasis needs to be laid on controlling accessibility to heritage. This distinction will be used to develop two families of regional cultural policies that can be implemented on local, regional, national and European level.

\section{A) Concrete Examples of Policies that Aim at Valorising Heritage:}

- all European member states possess a multitude of cultural treasures and are rich of cultural assets. There are no exceptions. These assets should be raised productive by deliberate policies. Examples of these policies are the construction of a creative cluster around the heritage, the development of cultural tourism and the valorisation of the assets with respect to the local population;

- although CHI offers opportunities to virtually all European regions, the research has clearly shown that urban and coastal areas are particularly rich of CHI. All policies regarding Europe's urban and 
coastal areas should possess a cultural dimension; better still is to give Europe's cultural policy a distinct urban and coastal dimension;

- cultural heritage and cultural landscapes are basic conditions for the development of creative industries, the potential powerhouses of the post-industrial economy similar to what the textile and steel industries were for the industrial economy. Regional policies should favour the creation of the conditions (for example investments in education, cultural facilities, and so on) of the growth of the creative industry;

- adopt policies that aim at internalising the positive effects of cultural development policies. The spill-over of the positive effects make it harder to autonomously sustain cultural investments. Hence, Territorial Impact Assessments should be dealing explicitly with the spatial distribution of impacts;

- social and economic marginality may lead to cultural depauperisation. On one hand social and economic decline may help to erode the financial basis that is necessary to maintain heritage. On the other, loss of identity and erosion of heritage undermines the competitive position of the region and hence may lead to social and economic decline. This vicious circle may be broking by valorisation of cultural assets;

- transport policies should stimulate the accessibility of heritage there where use is insufficient, for example by implementing Park\&Ride schemes and public transport reserved for visitors, and investments should be made in the application of ITC (e.g. promoting the production and distribution of CD-ROMS, Internet) in guaranteeing and managing access, not only from a physical point of view;

- accessibility heritage and hence the use of it may also be improved by stimulating the creation of heritage systems. These heritage systems may be a direct result of an art-historic interpretation of the European territory;

- the involvement of private partners and non-governmental organisations in the maintenance and the "mise en valeur" of cultural heritage and landscapes should be encouraged by offering specific financial incentives (subsidies) and by implementing tax incentives (special VAT rates; possibility to deduce contributions form the income).

\section{B) Concrete Examples of Policies that Aim at Conserving Cultural} Heritage:

- all the traditional investment schemes regarding the physical maintenance of cultural heritage should be accompanied by a sound strategy related to the use of the conserved objects; examples may be public offices, libraries, exposition space, student housing;

- the development of cultural tourism brings about both benefits and huge, often underestimated costs. These effects can only become visible if systematic Territorial Impact Assessments are being 
executed. More should therefore be done to limit the damages that tourism may generate. Examples of Visitor management policies (computerised reservation systems, intelligent guidance by palm computer, city cards, visitors centres on terminals) that are based on the analysis of the carrying capacity should be studied and implemented;

- tax incentives (reduced VAT; special deductions on income tax) should make it easier for private parties to engage in conservation;

- social housing policies and urban regeneration policies may help to sustain conservation of cultural heritage;

- multicultural and multi-ethnical societies provide positive impulses to regions that strive for social and economic development and should be explicitly perceived as such in regional policies;

- cultural landscapes and the earlier mentioned systems of cultural heritage do not respect administrative boundaries at all. The opportunities for cross-border, trans-national and interregional programmes and development projects should be captured by local and regional authorities with enthusiasm and promoted by the European Union;

- Europe presents a limited number of cultural clusters, of cultural hotspots, that may well become the continent's post-industrial growth poles. These clusters should be nurtured with care;

- cultural excellence and regional competitiveness are strictly interrelated. Policies that enhance cultural excellence and cultural innovation therefore improve the region's overall competitiveness;

- specially developed education schemes on all levels of education, also those developed on a local scale, favour the understanding of culture and stimulates cultural participation.

Cultural heritage protection, planning and policies should not be seen separately. Rather they should be integrated in other aspects of planning like economic or traffic development and treated with a mixed instrument tool case and by professionals from different fields.

Although an integration of findings and policies on an EU-wide level is desirable and necessary, a focus on local and regional decisions and measures should not be forgotten for two reasons: First of all, it is on local or regional level, where the cultural development takes place. All actions in this context give the cultural landscapes their regional identity and intrinsic value. A second reason is that most measures only work when accepted by and done in co-operation with people that live and work there; without the commitment of all stakeholders, the concerned actions will not prove to be successful on the long term.

All discussions about policy options should recognise that the final decision about the direction in which cultural heritage will evolve should be taken in agreement with the locals and their bottom-up visions. The involvement of the different representatives of the stakeholder groups is of the utmost 
importance to make interventions last in time. This has become very clear in many of the case studies that have been previously illustrated.

\section{Towards a European Observatory for Cultural Landscapes, Cultural Heritage and Cultural Policies}

As was mentioned already, the quantity and the quality of statistical information regarding cultural heritage at a European level is absolutely insufficient. Notwithstanding the increasing importance of the sector as a source of regional development, are Europe-wide statistics regarding cultural assets non existent.

One of the principal merits of the ESPON programme regarding cultural heritage is that through intensive collaboration in the network of the Universities and the Research Institutes that made of the TGP of 1.3.3, an important start has been made to construct such a data-base that should help to overcome this important shortcoming. The assembly of a European database from national sources poses some problems of its own, among others the comparability of statistical information because of the lack of harmonisation of the definitions on which the statistics are based and the occasional character of cultural censuses in may of the member countries, problems that were solved as good as possible while the project evolved.

A special problem that emerged frequently and that was only partly solved was that of the value of the single objects (should Rome's Colosseo, for example, be counted the same way as a listed country house in the Netherlands?). The approach that was chosen here was that already experimented in the SPESP programme, that is to use the evaluations that tourist guides propose of monuments and museums. Another problem regards the gathering of statistics on immaterial cultural heritage and identity. The issues dealing with immaterial heritage and identity have been covered extensively in the case studies. The European Observatory should make particular efforts to address these two problems systematically.

In fact, one basic condition to either preserve or valorise cultural heritage, a theme that is especially relevant for cultural landscapes, is their systematic and continuous registration by national and regional authorities. While a number of useful landscape typologies and maps of the geographic distribution have been developed by the ESPON TGP on a national level, European approaches are still facing severe problems in terms of scale, accuracy and political relevance.

As one unique register for cultural heritage is not set up yet on the EU-level, stocktaking has to be done along a standardised classification system. This is true for both cultural landscapes and cultural heritage. Therefore a European-wide neutral cultural landscape typology system is needed which 
forms the baseline for an accentuation and evaluation of cultural landscapes which may be graded afterwards. Also a Europe-wide inventory of built cultural heritage has so far been missing. A beginning has been made in this project, but further work is still necessary. Every European cultural landscape and heritage city, site or monument should find a proper place in such a typology system. As far as the single parts of cultural heritage are concerned, further studies on the issues on the carrying capacity of cultural assets are urgently needed.

The starting point of such an Observatory as far as cultural heritage is concerned should be the methodological discussion and the meta-data base that has been presented in the final report .

Apart of laying a sound basis for a Europe-wide information system on cultural landscapes and cultural heritage, the Observatory should be able to supply reliable information on cultural policies on regional, national and community level. It could contain information regarding best practices, be engaged in benchmarking as far as cultural policy is concerned, and deliver information on sensitive issues such as the way property rights are managed, and the way cultural development is funded and how cultural development relates to regional change.

The European Observatory for Cultural Landscapes, Cultural Heritage and Cultural Policies should be a joint-venture of (at least) the European Union, UNESCO ( that has already started to work on a cultural observatory) and the Council of Europe. Other potential partners may be non-governmental organisations like ICOMOS and ICROM. In any case, to play an effective role in policy making and to oversee and control the way article 151 of the Amsterdam Treaty is implemented, an independent status of the Observatory is an absolute must. 


\section{References}

Allen J, Massey D., and Cochrane A.D. (1998) Rethinking the region. London: Routledge.

Ambrose T. and Paine C. (1993) Museum Basics. London: ICOM and Routledge.

Aplin G. (2002), Heritage identification, conservation, and management. Melbourne: Oxford University Press.

Arnould E. and Pedrin S. (1993) "Developpement touristiques et dimensions transfrontalières: le cas de l'espace Gaume - Meuse du Nord”. Revue de Géographie de l'Est 33(3) 191-204.

Borg J. van der (1993) The Social Carrying Capacity of Venice. Rotterdam: EURICUR report (1993-8).

Borg, J. van der, and G. Gotti (1995) Tourism and Cities of Art. UNESCO/ROSTE Technical Report n. 20, Venice.

Borg, J. van der. (ed.) (1996) Alternative tourism routes in cities of art. UNESCO-ROSTE Technical Report n. 23, Venice.

Bradburne J. (2000) The poverty of nations: Should museums create identity? in Fladmark, J.M. (ed) Heritage and Museums Shaping National Identity. Shaftesbury: Donhead Publishing Ltd. 379 - 393.

Butler R.W. (1980) “The Concept of a Tourist area Cycle of Evolution: Implications for Management of Resources”. Canadian Geographer 24(1): 5-12.

Canestrelli, E. and P. Costa (1991), "Tourist Carrying Capacity: a Fuzzy Approach”. Annals of Tourism Research 18 (2): 295-311.

Castells M. (1996) The information age: Economy, society and culture. Volume I: The rise of the network society. Oxford: Blackwell.

Davison G. (1991) The Meanings of Heritage. Sydney: Allen and Unwin.

Davison G. (2000) The use and abuse of Australian history. Sydney: Allen and Unwin.

De Pater B. et al. (2002) Denken over regio’s. Geografische perspectieven. Bussum: Coutinho. 
Diekmann A. (2004) Bridging the gap: an indicative approach to the relationship between built heritage preservation and tourist consumption. Université Libre de Bruxelles, Unpublished Ph.D. Thesis.

Dziembowska-Kowalska J. and Funck R.H. (2000), “Cultural Activities as a Location Factor in European Competition Between Regions: concepts and Some Evidence”. Annals of Regional Science 34: 1-12.

Eiden G. (2001) Landscape indicators. In: Eiden, G., Bryden, J., Piorr, H.-P. (Eds.), Proposal on Agri-Environmental Indicators (PAIS). Final Report of the PAIS Project. Luxembourg: EUROSTAT.

European Commission (2004) The Spiritual and Cultural Dimension of Europe Unpublished paper, Vienna and Brussels.

Feilden B.M. and Jokilehto J. (1998) Management Guidelines for World Cultural heritage Sites. Rome: ICCROM.

Fladmark J. (ed) (2000) Heritage and Museums, Shaping National Identity. Oxford: Alden Press.

Giddens, A. (1984) The Constitution of Society: Introduction of the Theory of Structuration. University of California Press, Berkeley

Graham B., Ashworth G.J. and Tunbridge J.E. (1998) A Geography of Heritage: Power, Culture and Economy. London: Arnold.

Gravari-Barvas M.V. (2003) Lieux de Culture. Culture des lieux. Espaces et Territoires Presses Universitaires de Rennes.

Heilbrun J. (1992) “Art and Culture as Central Place Functions”. Urban Studies 29 (2): 205-215.

Jansen-Verbeke M. (1999) "Industrial heritage: a nexus for sustainable tourism development”. Tourism Geographies, An International Journal of Tourism Space, Place and Environment 1(1): 70-85.

Jansen-Verbeke M. and Lievois E. (1999) Analysing heritage resources for urban tourism in European Cities. In: Contemporary Issues in Tourism Development, Pearce, D.G., Butler, R.W. (eds). London: Routledge, 81-107.

Keating M. (2001) “Rethinking the region”. European Urban and Regional Studies 8: 217-234.

Lindberg K., McCool S. and Stankey G. (1997) "Rethinking Carrying Capacity”. Annals of Tourism Research 24 (2): 461-465. 
Martin B.S. and Uysal M. (1990) "An Examination of the Relationship Between Carrying Capacity and the Tourism Lifecycle: Management and Policy Implications”. Journal of Environmental Management 31: 327-333.

Martinotti, G. (1993), Metropoli. La Nuova Morfologia Sociale della Città. Bologna: il Mulino

McKercher B. and du Cros J. (2002) Cultural Tourism. The partnership between Tourism and Cultural Heritage Management. Haworth Hospitality Press.

Montanari A. and Williams A. (1996) European Tourism: Regions, Spaces and restructuring. Chicester. John Wiley \& Sons.

Moreno Y.J., Santagata W., and Tabassum A. (2004) "Material cultural heritage, cultural diversity, and sustainable development". Paper presented at the $13^{\text {th }}$ annual conference of ACEI, Chicago, USA, 3-5 June 2004.

Patrin V. (1997) Tourisme et patrimoine en France et en Europe. Paris: Les études de la documentation Française.

Renes H. (1999) “Landschap en regionale identiteit”. Geografie 8 : 8-14

Rubinstein J.M. (2004) The Cultural Landscape. New Jersey: Pearson Prentice Hall.

Russo A.P. (2004) "Crowding, Carrying Capacity and the TALC Model”. In The Tourist Area Life Cycle: Conceptual And Theoretical Issues, ed. by R. Butler. Channel View Publications, Clevedon, in press.

Russo, A.P. (2002) “A Stakeholders Approach to Tourism Policy in Bruges”. In Tourism Studies in Bruges, ed. by WES, Bruges.

Russo, A.P. (ed.) (2000), Tourism Management in Heritage Cities. Proceedings of the 2nd International Seminar, Nazareth, Israel, 3-5 February 2000. UNESCO Venice Office Technical Reports Series, n. 30.

Russo, A.P., Boniface P., and Shoval N. (2001) "Tourism Management in Heritage Cities”. Annals of Tourism Research 28(3): 824-826

Santagata W. (2004) Cultural Districts. In V. Ginsbourg and D. Throsby (Eds.) Handbook on the Economics of Art and Culture. Amsterdam: ElsevierScience, forthcoming.

Scott A.J. (2000) The Cultural Economy of Cities. London: Sage Publications. 
Smiers J. (2002) The Role of the European Community Concerning the Cultural Article 151 in the Treaty of Amsterdam, Unpublished Research Paper, Utrecht School of the Arts.

Timothy D.J. (2001) Tourism and Political Boundaries. London: Routledge. 